\title{
SportR \iv
}

Part of the Society for Transparency,

Openness and Replication in

Kinesiology (STORK)
Preprint

not peer reviewed

\section{Physical inactivity: A behavioral disorder in the physical therapist's scope of practice}

\author{
Matthieu P. Boisgontier ${ }^{1,2,}{ }^{*}$, Maura D. Iversen ${ }^{3-5}$
}

\begin{abstract}
${ }^{1}$ Faculty of Movement and Rehabilitation Sciences, KU Leuven, Belgium; ${ }^{2}$ Department of Physical Therapy, University of British Columbia, Canada; ${ }^{3}$ College of Health Professions, Sacred Heart University, Fairfield, CT; ${ }^{4}$ Department of Medicine, Section of Clinical Sciences, Brigham and Women's Hospital, Harvard Medical School, Boston, Massachusetts; ${ }^{5}$ Department of Women's and Children's Health, Karolinska Institute, Stockholm, Sweden. *For correspondence: boisgontiermatthieu@gmail.com; @MattBoisgontier
\end{abstract}

Please cite as: Boisgontier MP, Iversen MD (2019) Physical inactivity: A behavioral disorder in the physical therapist's scope of practice. SportRXiv. DOI: 10.31236/osf.io/cqv48

This article has been accepted for publication in Physical Therapy published by Oxford University Press.

\section{INTRODUCTION}

Physical activity is considered a strategy to improve health. This reasoning implies that physical inactivity is the reference behavior, which is not the case. In health, the gold standard is a state of complete physical, mental and social well-being. ${ }^{1}$ Physical inactivity involves a higher risk of cardiovascular disease ${ }^{2}$, hypertension ${ }^{3}$, diabetes ${ }^{2,4}$, cancer ${ }^{5}$, depression ${ }^{6}$, and obesity ${ }^{7}$. Moreover, 6 to $10 \%$ of all deaths from noncommunicable diseases worldwide can be attributed to physical inactivity. ${ }^{8}$ Therefore, physically active individuals appear to be closer to the health gold standard than inactive individuals. Physical activity - not inactivity - should be the standard reference behavior. In this reversed framework, physical inactivity becomes a clinically significant disturbance in an individual's behavior, which is the definition of a behavioral disorder. ${ }^{9}$ Therefore, physical inactivity should be treated as such.

\section{PHYSICAL INACTIVITY DISORDER}

During the past two decades, society has encouraged people to be more physically active..$^{8,10}$ As a result, most individuals are now aware of the positive effects of regular physical activity and have the intention to be active. ${ }^{11}$ Yet, this intention is not sufficient alone, as engagement in physical activity is often not 
executed. ${ }^{12}$ The World Health Organization (WHO) defines impulse control disorders, a specific type of behavioral disorder, as "the repeated failure to resist an impulse, drive, or urge to perform an act that is rewarding to the person, at least in the short-term, despite consequences such as longer-term harm either to the individual or to others, marked distress about the behavior pattern, or significant impairment in personal, family, social, educational, occupational, or other important areas of functioning." ${ }^{\prime 2}$ Physical inactivity, which is characterized by the repeated failure to resist an impulse, drive, or urge to minimize energy expenditure, ${ }^{13}$ matches this definition perfectly.

\section{DIAGNOSIS}

From a health perspective, physical inactivity, also named insufficient physical activity ${ }^{14}$, is defined as the failure to meet the recommendations on physical activity for health. The latest recommendations from the $\mathrm{WHO}^{15}$ and the US Department of Health and Human Services ${ }^{16}$ address multiple population groups. Preschool-aged children aged 3-5 years should be physically active throughout the day. Children and adolescents aged 6-17 should do $60 \mathrm{~min}$ or more of moderate-to-vigorous physical activity daily. Throughout the week, adults aged 18-64 and older adults age 65 years and above should do at least 150 min of moderate-intensity, or 75 min of vigorous-intensity aerobic physical activity, or an equivalent combination of moderate- and vigorous-intensity aerobic activity. They should also do musclestrengthening activities on 2 or more days a week. Pregnant and postpartum women should do at least $150 \mathrm{~min}$ of moderate-intensity aerobic activity a week. Adults with chronic conditions or disabilities, who are able, should follow the key guidelines for adults and do both aerobic and muscle-strengthening activities.

\section{EPIDEMIOLOGY}

The most recent data from 1.9 million participants representing $96 \%$ of the world's population shows that more than a quarter of all adults are physically inactive, which represents more than 1.4 billion adults. ${ }^{14}$ The prevalence of physical inactivity are highest in Latin America, the Caribbean, high-income Western countries, and high-income Asia Pacific. These data also confirmed previous findings ${ }^{17}$ demonstrating higher levels of physical inactivity in women than in men, with some of the biggest differences in south and central Asia, the Middle East, and north Africa. While multiple articles mention a pandemic of physical inactivity, ${ }^{17,18}$ the global prevalence of physical inactivity was stable between 2001 and 2016 with an average change across the 65 countries of less than $0.01 \% .{ }^{14}$ Yet, wide variations in physical inactivity were observed across countries. Levels of physical inactivity were increasing in 37 countries, whereas they were decreasing in 28 countries. The largest increases $(>15 \%)$ occurred in high-income countries such Germany and Singapore, while the largest decreases ( $>15 \%)$ occurred in east and southeast Asia.

\section{ETIOLOGY}

Recent findings suggest that physical inactivity disorder is caused by the combination of genetic, cerebral, and environmental factors. A study including monozygotic and dizygotic twin pairs assessed the heritability of physical activity and sedentary behavior. ${ }^{19} \mathrm{~A}$ sedentary behavior is defined as any waking behavior characterized by an energy expenditure $\leq 1.5$ metabolic equivalents (METs), while in a sitting, reclining or lying posture. ${ }^{20}$ Results showed that genetic factors explained $47 \%$ of the variance in the time 
spent in moderate-to-vigorous intensity physical activity and $31 \%$ of the variance in the time spent in sedentary behavior. These results suggested that innate biological processes may be driving some of our daily physical inactivity. This suggestion was supported by findings of an electroencephalography study investigating the cortical activity underlying automatic approach and avoidance of physical activity and sedentary behaviors. ${ }^{21}$ Results showed that avoiding sedentary behaviors (vs. physical activity) was associated with higher conflict monitoring and higher inhibition. These results suggest that the human brain is automatically attracted to sedentary behaviors and requires additional cortical resources to counteract this attraction. This suggestion was supported by epidemiological data showing that lower cognitive resources predict higher levels and faster increase of physical inactivity across aging. ${ }^{22}$ Poor environmental factors such as neighborhood conditions also increase the odds of being physically inactive $^{23}$, but higher cognitive resources reduce this adverse influence. ${ }^{24}$

\section{PATHOPHYSIOLOGY}

Physical inactivity disorder is associated with a loss of lean body mass, which is the result of a chronic imbalance between muscle protein synthesis and breakdown. ${ }^{25}$ This imbalance can be exacerbated during the progression of aging and lead to sarcopenia ${ }^{26}$, which is characterized by progressive and generalized loss of skeletal muscle mass and strength. Sarcopenia is a major contributor to the risk of physical frailty, functional impairment, poor health-related quality of life, and premature death. ${ }^{27}$ Physical inactivity disorder is associated with a reduced bone density ${ }^{28}$, which increases bone fragility and constitutes a risk factor for osteoporosis. ${ }^{29}$ Physical inactivity disorder is associated with higher fat mass ${ }^{30}$ and being overweight or obese ${ }^{7}$. Physical inactivity disorder is also a risk factor for cardiovascular disease ${ }^{2}$, hypertension ${ }^{3}$, diabetes ${ }^{2,4}$, $^{\text {cancer }}{ }^{5}$, and depression ${ }^{6}$.

\section{PROGNOSIS}

Based on data from the National Institutes of Health-American Association of Retired Persons, adults who were consistently inactive throughout adulthood were at higher risks for all-cause, cardiovascular diseaserelated, and cancer-related mortality than physically activity individuals. ${ }^{32}$ Yet, increasing physical activity later in adulthood (40-61 years) was associated with lower mortality risk that was similar to those associated with being physically active across the adult life course (15-61 years). These results suggest that midlife is not too late to begin engaging in physical activity for health.

\section{EDUCATION \& REHABILITATION}

Physical therapists are experts in physical activity, defined as any bodily movement produced by skeletal muscles that requires energy expenditure - including activities undertaken while working, playing, carrying out household chores, travelling, and engaging in recreational pursuits. ${ }^{33}$ This expertise should be used to help people reach the recommendations of physical activity to optimize their health and extend their life, no matter their age. Physical therapists should serve as primary educators regarding the idea that physical inactivity is a behavioral disorder resulting from multidimensional factors. Being aware of these factors, such as our automatic attraction to energetic cost minimization ${ }^{13,21}$, is the first step towards a more active lifestyle. For instance, greater awareness regarding physical inactivity can lead to the 
development of cognitive or environmental strategies to counteract this automatic attraction. Physical therapists should also inform the public that being physically active ${ }^{15,16}$ does not necessarily require specific exercise - a subset of physical activity that is planned, structured, and repetitive ${ }^{33}$ - or doing sport - which involves competition. Walking in the street is also a physical activity. Individuals performing the least physical activity benefit most by even modest increases in moderate-to-vigorous physical activity. ${ }^{16}$ Physical therapists should emphasize that clients cannot afford to miss out on this inexpensive path to a healthier life. Recommendations emphasize that moving more and sitting less will benefit nearly everyone. ${ }^{16}$ Another central point to the rehabilitation of physical inactivity is to monitor the pleasure associated with different intensities of physical activity ${ }^{34}$. This pleasure is likely to foster longer engagement in the activity, especially when it is experienced at the end of the activity. ${ }^{35}$ Additional research is required to establish evidenced-based protocols supporting the return to physical activity.

\section{CONCLUSION}

Physical inactivity should not be considered a physiological behavior as it perfectly matches the definition of a behavioral disorder. This definition more accurately conceptualizes physical inactivity and clearly emphasizes the necessity to provide care for physically inactive people. Physical therapists are key health professionals in rehabilitating this disorder. This article also highlights the necessity to further investigate the etiology of this disorder. This understanding is critical to the implementation of efficient rehabilitation programs - by physical therapists or in collaboration with other health professionals - to ensure patients receive comprehensive care aiming to cure a physical inactivity disorder.

\section{REFERENCES}

[1] World Health Organization. Constitution. https://www.who.int/about/who-we-are/constitution. Accessed August 2019.

[2] Wahid A, Manek N, Nichols M, et al. Quantifying the association between physical activity and cardiovascular disease and diabetes: a systematic review and meta-analysis. J Am Heart Assoc. 2016;5(9):e002495. https://doi.org/10.1161/JAHA.115.002495

[3] Liu X, Zhang D, Liu Y, et al. Dose-response association between physical activity and incident hypertension: a systematic review and meta-analysis of cohort studies. Hypertension.

2017;69(5):813-820. https://doi.org/10.1161/HYPERTENSIONAHA.116.08994

[4] Aune D, Norat T, Leitzmann M, Tonstad S, Vatten L. Physical activity and the risk of type 2 diabetes: a systematic review and dose-response meta-analysis. Eur J Epidemiol. 2015;30(7):529-542. https://doi.org/10.1007/s10654-015-0056-z

[5] Moore SC, Lee IM, Weiderpass E, et al. Association of leisure-time physical activity with risk of 26 types of cancer in 1.44 million adults. JAMA Intern Med. 2016;176(6):816-825.

https://doi.org/10.1001/jamainternmed.2016.1548

[6] Schuch F, Vancampfort D, Firth J, et al. Physical activity and sedentary behavior in people with major depressive disorder: a systematic review and meta-analysis. J Affect Disord. 2017;210:139-150. https://doi.org/10.1016/j.jad.2016.10.050

[7] Bleich SN, Vercammen KA, Zatz LY, Frelier JM, Ebbeling CB, Peeters A. Interventions to prevent global childhood overweight and obesity: a systematic review. Lancet Diabetes Endocrinol. 2018;6(4):332346. https://doi.org/10.1016/S2213-8587(17)30358-3 
[8] Lee IM, Shiroma EJ, Lobelo F, et al. Effect of physical inactivity on major non-communicable diseases worldwide: an analysis of burden of disease and life expectancy. Lancet. 2012;380(9838):219-229. https://doi.org/10.1016/S0140-6736(12)61031-9

[9] World Health Organization. ICD-11 for mortality and morbidity statistics. https://icd.who.int/browse11/I-m/en. Accessed August 2019.

[10] Chodzko-Zajko WJ. The World Health Organization issues guidelines for promoting physical activity among older persons. J Aging Phys Act. 1997;5:1-8. https://doi.org/10.1123/japa.5.1.1

[11] Canadian Fitness and Lifestyle Research Institute. Physical activity monitor: facts and figures. http://www.cflri.ca/sites/default/files/node/95/files/PAM2008FactsFigures_Bulletin14_Intention_t o_be_activeEN.pdf. Accessed August 2019.

[12] Rhodes RE, Plotnikoff RC, Courneya KS. Predicting the physical activity intention-behavior profiles of adopters and maintainers using three social cognition models. Ann Behav Med. 2008;36(3):244252. https://doi.org/10.1007/s12160-008-9071-6

[13] Cheval B, Radel R, Neva JL, et al. Behavioral and neural evidence of the rewarding value of exercise behaviors: a systematic review. Sports Med. 2018;48(6):1389-1404. https://doi.org/10.1007/s40279-018-0898-0

[14] Guthold R, Stevens GA, Riley LM, Bull FC. Worldwide trends in insufficient physical activity from 2001 to 2016: a pooled analysis of 358 population-based surveys with 1.9 million participants. Lancet Glob Health. 2018;6(10):e1077-e1086. https://doi.org/10.1016/S2214-109X(18)30357-7

[15] World Health Organization. Global recommendations on physical activity for health. https://apps.who.int/iris/bitstream/handle/10665/44399/9789241599979_eng.pdf?sequence=1. Accessed August 2019.

[16] Piercy KL, Troiano RP, Ballard RM, Carlson SA, Fulton JE, Galuska DA, George SM, Olson RD. The physical activity guidelines for Americans. JAMA. 2018;320(19):2020-2028. https://doi.org/10.1001/jama.2018.14854

[17] Althoff T, Sosič R, Hicks JL, King AC, Delp SL, Leskovec J. Large-scale physical activity data reveal worldwide activity inequality. Nature. 2017;547(7663):336-339. https://doi.org/10.1038/nature23018.

[18] Kohl HW 3rd, Craig CL, Lambert EV, et al. The pandemic of physical inactivity: global action for public health. Lancet. 2012;380(9838):294-305. https://doi.org/10.1016/S0140-6736(12)60898-8.

[19] den Hoed M, Brage $S$, Zhao JH, et al. Heritability of objectively assessed daily physical activity and sedentary behavior. Am J Clin Nutr. 2013;98(5):1317-1325. https://doi.org/10.3945/ajcn.113.069849

[20] Tremblay MS, Aubert S, Barnes JD, et al. Sedentary behavior research network (SBRN) - terminology consensus project process and outcome. Int J Behav Nutr Phys Act. 2017;14(1):75. https://doi.org/10.1186/s12966-017-0525-8

[21] Cheval B, Tipura E, Burra N, et al. Avoiding sedentary behaviors requires more cortical resources than avoiding physical activity: an EEG study. Neuropsychologia. 2018;119:68-80. https://doi.org/10.1016/j.neuropsychologia.2018.07.029.

[22] Cheval B, Orsholits D, Sieber S, Courvoisier D, Cullati S, Boisgontier MP. Age-related decline of cognitive resources precedes and explains the decline in physical activity. SportRxiv. 2019. https://doi.org/10.31236/osf.io/pagx6

[23] Xiao Q, Keadle SK, Berrigan D, Matthews CE. A prospective investigation of neighborhood socioeconomic deprivation and physical activity and sedentary behavior in older adults. Prev Med. 2018;111:14-20. https://doi.org/10.1016/j.ypmed.2018.02.011 
[24] Cheval B, Rebar AL, Miller MW, et al. Cognitive resources moderate the adverse impact of poor perceived neighborhood conditions on self-reported physical activity of older adults. Prev Med. 2019;126:105741. https://doi.org/10.1016/j.ypmed.2019.05.029

[25] Phillips SM, Parise G, Roy BD, Tipton KD, Wolfe RR, Tamopolsky MA. Resistance-training-induced adaptations in skeletal muscle protein turnover in the fed state. Can J Physiol Pharmacol. 2002;80(11):1045-1053. https://doi.org/10.1139/y02-134

[26] Foong YC, Chherawala N, Aitken D, Scott D, Winzenberg T, Jones G. Accelerometer-determined physical activity, muscle mass, and leg strength in community-dwelling older adults. J Cachexia Sarcopenia Muscle. 2016;7(3):275-283. https://doi.org/10.1002/jcsm.12065

[27] Janssen I, Shepard DS, Katzmarzyk PT, Roubenoff R. The healthcare costs of sarcopenia in the United States. J Am Geriatr Soc. 2004;52(1):80-85. https://doi.org/10.1111/j.15325415.2004.52014.x

[28] Johansson J, Nordström A, Nordström P. Objectively measured physical activity is associated with parameters of bone in 70-year-old men and women. Bone. 2015;81:72-79. https://doi.org/10.1016/j.bone.2015.07.001

[29] Castrogiovanni P, Trovato FM, Szychlinska MA, Nsir H, Imbesi R, Musumeci G. The importance of physical activity in osteoporosis. From the molecular pathways to the clinical evidence. Histol Histopathol. 2016;31(11):1183-1194. https://doi.org/10.14670/HH-11-793

[30] Staiano AE, Martin CK, Champagne CM1, Rood JC, Katzmarzyk PT. Sedentary time, physical activity, and adiposity in a longitudinal cohort of nonobese young adults. Am J Clin Nutr. 2018;108(5):946952. https://doi.org/10.1093/ajcn/nqy191

[31] Wroblewski AP, Amati F, Smiley MA, Goodpaster B, Wright V. Chronic exercise preserves lean muscle mass in masters athletes. Phys Sportsmed. 2011;39(3):172-178. https://doi.org/10.3810/psm.2011.09.1933

[32] Saint-Maurice PF, Coughlan D, Kelly SP, et al. Association of leisure-time physical activity across the adult life course with all-cause and cause-specific mortality. JAMA Netw Open. 2019;2(3):e190355. https://doi.org/10.1001/jamanetworkopen.2019.0355

[33] Caspersen CJ, Powell KE, Christenson GM. Physical activity, exercise, and physical fitness: definitions and distinctions for health-related research. Public Health Rep. 1985;100(2):126-131.

[34] Ekkekakis P, Parfitt G, Petruzzello SJ. The pleasure and displeasure people feel when they exercise at different intensities: decennial update and progress towards a tripartite rationale for exercise intensity prescription. Sports Med. 2011;41(8):641-671. https://doi.org/10.2165/11590680000000000-00000

[35] Kahneman D, Fredrickson BL, Schreiber CA, Redelmeier DA. When more pain is preferred to less: adding a better end. Psychol Sci. 1993;4:401-405. https://doi.org/10.1111/j.1467-

9280.1993.tb00589.x 